Research Square
Preprints are preliminary reports that have not undergone peer review.

They should not be considered conclusive, used to inform clinical practice, or referenced by the media as validated information.

\title{
Optimization of process parameters for the green synthesis of silver nanoparticles using Plackett-Burman and 3-level Box-Behnken Design
}

Halima R ( $\sim$ halimajenish@gmail.com )

Sir M Visvesvaraya Institute of Technology https://orcid.org/0000-0001-8115-4906

Archna Narula

MS Ramaiah University of Applied Sciences

R.R Sivakiran

MS Ramaiah Institute of Technology

\section{Research}

Keywords: optimization, Silver Nanoparticle, green synthesis, Plackett-Burman Design (PBD), 3-level Box-Behnken Design(BBD)

Posted Date: September 28th, 2020

DOI: https://doi.org/10.21203/rs.3.rs-72146/v1

License: () (i) This work is licensed under a Creative Commons Attribution 4.0 International License. Read Full License 


\section{Abstract \\ Background:}

The present work describes the synthesis of silver nanoparticles (AgNps) from leaf extracts of Piper betle and Jatropha curcas using a green approach. Green synthesis of nanoparticle is superior over other methods of synthesis as it is ecofriendly and cost effective. The phytochemical components in the leaf extract play a vital role in reducing the $\mathrm{AgNO}_{3}$ and hence synthesizing the silver nanoparticles. During this reduction activity, the several factors which affect the synthesis of nanoparticles were investigated and optimized according to the yield of nanoparticles. The experimental conditions investigated were $\mathrm{pH}$, temperature, pressure, time of reaction, microwave radiation, UV radiation and concentration of plant extract, silver nitrate \& sunlight. Satisfactory yields of silver nanoparticles synthesis from plant extract were obtained by using optimum conditions when compared to conventional synthesis of nanoparticles. The optimization parameter was later

\section{Result:}

A mathematical model was formulated to correlate the interactive influence of the parameters and the significant reduction. Plackett-Burman design (PBD) indicated that concentration of plant extract, concentration of silver nitrate and sunlight were the major parameters affecting the synthesis of silver nanoparticle. The mutual interactions of these variables are mapped in the design by 3 Box-Behnken design (BBD). The significant factors and their interactions in the green synthesis were examined by analysis of Variance (ANOVA). The result indicated that the BBD was a good predictive model for the experimental results. Though the plant extracts are different, the characterization of the synthesized nanoparticle after optimization of parameters showed uniform size and shape i.e. spherical shape and size of $41 \mathrm{~nm}$.

\section{Conclusion:}

The silver nanoparticles were synthesized under different optimization parameters were uniformly shaped (spherical) and sized (41 nm) particles. The mathematical models Plackett-Burman and Box-Behnken helped in analyzing the impact of the optimization parameters.

\section{Background}

Nanoparticles are those of 1-100 nm size and are increasing attention due to wide applications in the areas of science and technology. Metal nanoparticles are gaining more importance due to their optical, electrical and catalytic properties. They are widely applied in various industries as medicine, water treatment, energy conversion, magnetics, mechanics and so on [1, 2]. Although there are various synthesis methods of Silver nanoparticles as chemical reduction [3], micro emulsion [4], photoreduction [5] and radiation [5]; green synthesis of AgNps serves as a more economical and eco friendly way of synthesizing. Though many physical, chemical and biological methods have been researched for nanoparticle synthesis, silver nanoparticles synthesized via physical and chemical methods cannot avoid the use of toxic agents. These methods rely on use of organic solvents and toxic chemical as N,Ndimethylformamide, sodium borohydride, and hydration hydrazine [6]. Green synthesis seems as an alternative ecofriendly and sustainable approach in synthesizing AgNps. Although the technology is proven to be cost effective it also takes into account environmental safety. The phytochemical components in the leaf extract: asterpenoids, flavones, ketones, aldehydes, amides and carboxylic acid play a vital role in the reducing activity of the silver nitrate solution. The secondary metabolites found in the plant extract as flavones, organic acids and quinines are water soluble metabolites and are responsible for its immediate reduction of ions. Green synthesis method thus enables better synthesis by fast reductions of ions. [7] However by optimizing various parameters as temperature, pH more stable and size controlled nanoparticles can be synthesized. The optimization of synthesis through statistical method is more effective when compared with classical. [8]

The literature says that the extracts of various plants have been employed for the synthesis of silver nanoparticles like Neem leaf [10], Aloe vera [11], xerophytes (Bryophyllum sp)., mesophyte (Cyperus sp.),hydrophyte (Hydrilla sp.) [12], Gliricidia sepium, [13], Rosa rugosa [14], Chenopodium album [15], Cycas leaf [16], Acalypha indica [17], Cassia fistula [18], Hibiscus rosasinensis [19], weeds as Ipomoea aquatica, Enhydra fluctuans and Ludwigia adscendens [20], Psidium guajava [21], mangosteen leaf [22], Ocimum sanctum [23], Cocosnucifera coir extract [24], etc. It is observed that comparatively microorganisms mediated synthesis of metallic nanoparticles are faster to plant mediated synthesis. Plant metabolites had shown faster rate of reduction of metal ions and produces stable metallic nanoparticles. By using plant extracts for the synthesis of nanoparticles, the shape and size of the nanoparticles can be controlled and altered by modifying certain conditions as $\mathrm{pH}$ and temperature [25]

In the present work, the green synthesis of silver nanoparticles is carried out from two sources namely, Piper betle and Jatropha curcas. The various factors affecting the synthesis of silver nanoparticles as concentration of $\mathrm{AgNO}_{3}$, concentration of plant extract, $\mathrm{pH}$, temperature, time, microwave radiation, $\mathrm{UV}$

Radiation exposure, sun light exposure reaction, volume and pressure, etc. were studied. The optimization of these parameters was carried out by Placket Burman design to study the effect of these variables in the synthesis of silver nanoparticles. During synthesis of silver nanoparticles preliminary individual experiments were carried out to establish accurate range of process variables considered for optimization. These parameter ranges were screened for the best three significant factors by Plackett-Burman design (PBD). PBD is a very efficient design when only main effects are of interest. They use the minimum number of runs to quickly identify the factors with a significant effect on the response. Further three significant factors were selected using PBD, and then the significant variables were further optimized by Box-Behnken design (BBD) to determine the optimum levels of these optimized parameters to have a high yield of silver nanoparticles from plant extracts. BBD are of advantage in addressing the issue of where the experimental boundaries should be and in particular to avoid treatment conditions that are extreme. Two statistical tools, Plackett-Burman design (PBD) combined with Box-Behnken design (BBD) offered efficient and effective process mode for experiments. The optimized conditions were then used for synthesize of silver nanoparticles and it was observed that uniform size and shaped nanoparticles were obtained. 


\section{Results And Discussion}

\section{Green synthesis of Silver nanoparticle:}

The reduction activity of $\mathrm{Ag}^{+}$to $\mathrm{Ag}^{0}$ is shown by the color change from light green to brown color. The concentration is calculated by a calibration graph measuring the optical density at $430 \mathrm{~nm}$. Figure 1 a) shows the plant extract of yellow color and b) shows the change of color to brown showing the reduction activity of the plant extract to silver nanoparticles. The phytochemical components present in the leaf extracts enable a quicker reduction of ions when compared to other biological methods. Flavones, organic acids and quinines present in the leaf extract are water soluble phytochemicals responsible for immediate reduction of Silver ions. These were confirmed through the phytochemical analysis and was found that in Piper bet/e Flavones were $32.5 \mathrm{mg} / \mathrm{g}$, organic acids $8 \%(\mathrm{w} / \mathrm{w})$ and quinines about $43 \mathrm{mg} / \mathrm{g}$. Similarly, the phytochemical components in Jatropha curcas Flavones were $37 \mathrm{mg} / \mathrm{g}$, organic acids $12 \%$ $(\mathrm{w} / \mathrm{w})$ and quinines about $39 \mathrm{mg} / \mathrm{g}$.

\section{Optimization of Silver nanoparticle:}

The optimization parameters influencing the silver nanoparticle synthesis were analyzed using Plackett burman design (PBD) and Box Behnken Design (BBD). The results obtained through the preliminary experiments were analyzed using statistica software.

\section{Plackett-Burman design (PBD):}

Plackett-Burman experimental design is most simple, less time consuming and well-established system for screening different variables and selection of most significant variable and conditions for better results. In our study, a total of 9 independent variables were screened using Plackett-Burman experimental design (Table 1).

The experiment was conducted in 12 runs to study the effect of the selected variables on the synthesis of silver nanoparticles. (Table 2). In present study, Plackett-Burman experimental design showed a markedly wide variation in yield of silver nanoparticles : $19.57-41.53 \mu \mathrm{g} / \mathrm{mL}$ in Piper betle extract and 20.46$41.51 \mu \mathrm{g} / \mathrm{mL}$ in Jatropha extract. This variation is mainly due to the effect of different optimization parameters on the synthesis of Silver nanoparticles and it has reflected the importance of optimization of variables to increase the yield of silver nanoparticles. The maximum yield of $41.53 \mu \mathrm{g} / \mathrm{mL}$ from Piper Betel extract and $41.51 \mu \mathrm{g} / \mathrm{mL}$ from Jatropha extract was achieved in the run number 1, while the minimum yield of $20.46 \mu \mathrm{g} / \mathrm{mL}$ from Piper betle extract and 19.57 $\mu \mathrm{g} / \mathrm{mL}$ from Jatropha extract were observed in the run number 12. The Run1 has $X_{1}, X_{3}, X_{7}$, and $X_{8}$ as the high value parameters and $X_{2}, X_{4}, X_{6}$ and $X_{10}$ as low value parameters. The results show that $\mathrm{pH}$, Pressure, concentration of plant extract and silver nitrate had a greater impact on nanoparticle synthesis. The plant extract has the reducing agent and the silver nitrate has the silver ion which is a major component for the silver nanoparticle synthesis. Pressure is also a contributing factor as increase in pressure influence the dynamic movement of the molecules resulting in more interaction and thereby synthesizing more nanoparticles. Change in $\mathrm{pH}$ contributes the $\mathrm{H}^{+}$ions there by changing the conformation of the reducing agent and hence allowing increasing the yield of nanoparticles. Also the Run 12 has the minimum yield on silver nanoparticle and all the parameters were kept at low level (-1) at this trial.

Table 3 show the effect of each independent variable on the silver nanoparticles synthesis. The values shows the determination of the effect of each variable and a large numerical value either positive or negative indicates that a factor has a large impact on synthesis; while an effect close to 0 means that a variable has little or no effect. With respect to the table we can see that seven variables out of nine namely, concentration of $\mathrm{AgNO}_{3}, \mathrm{pH}$, temperature, time, microwave radiation, sun light exposure have positive affect whereas other two variables namely, concentration of plant extract and UV radiation exposure. Regression coefficients estimate the unknown parameters and describe the relationship between a predictor variable and response. The sign of each coefficient indicates the direction of the relationship between a predictor variable and the response variable. Standard error is a measure of the statistical accuracy of an estimate, equal to the standard deviation of the theoretical distribution of a large population of such estimates. Main effect is the effect of one independent variable on the dependent variable. It ignores the effects of any other independent variables. P-value suggest us the significance of the parameter for the synthesis of nanoparticle

The Pareto chart shows the order of effects of nanoparticles synthesis (Figure 4). The length of each factor is proportional to the absolute values of the estimated effects. Therefore these terms are supporting hierarchy. The final decision on the most effective parameters requires the assessment of half-normal probability plot. Furthermore the positive and negative signs showed that the response is improved from the low to high level or not.

The Pareto chart shows 7 significant and 2 non-significant variables (Table 3) affecting the synthesis of silver nanoparticles. The leaf extract was the most significant variable with $\mathrm{p}$ value $=0.04$ (Piper bet/e) and 0.0002 (Jatropha curcas) as leaf extract has the major reducing agent in it, followed by silver nitrate with $\mathrm{p}$-value $=0.04$ ( Piper bet/e) and 0.0003 (Jatropha curcas) as silver nitrate contribute the silver ions for nanoparticle synthesis, sunlight exposure with $\mathrm{p}$ value $=0.07$ (Piper bet/e) and 0.001 (Jatropha) as sunlight serves as a photocatalyst for the reduction of silver ions, $\mathrm{pH}$ with $\mathrm{p}$-value $=0.015$ (Betel) and 0.011 (Jatropha curcas) as pH changes the structure of the reducing agent, Pressure with p-value $=0.19$ (Piper bet/e) and 0.003 (Jatropha curcas) and it influences the rate of , UV radiation with p-value $=0.20$ (Piper bet/e) and0.0005(Jatropha curcas) , MW radiation with p-value 0.47 (Piper bet/e) and 0.01 (Jatropha curcas) as it can proceed with the reduction activity with minimum time, Temperature with p-value $=0.57$ (Piper betle and 0.502(Jatropha curcas) as temperature increases the rate of interaction but the reducing agent may degrade at higher temperatures, and time with $\mathrm{p}$-value $=0.86($ Piper bet/e) and 0.0095(Jatropha), as time increases the synthesis of silver nanoparticles increases and after a while attains saturation due to non availability of silver ions or the reducing agent.

Table 4 is on ANOVA analysis and F-test. Analysis of variance (ANOVA) is used to determine whether there are any statistically significant differences between the means of three or more independent variables. ANOVA uses F-tests to statistically test the equality of means. The degrees of freedom associated with SSR will always be 1 for the simple linear regression model. The values from the ANOVA table shows that they are statistically significant. 
Table 5 shows the observed and predicted values of Silver Nanoparticles synthesis from the two leaf extracts Piper Betle and Jatropha curcas. The half normal probability plot was also used to identify the significant parameters. In this plot, The factors having effects near the straight line through zero are not significant while those deviating from the straight line are significant.[28] Figure 3 shows the half normal plot, can be used to which the algorithms of Length and Dong are applied to identify significant effects and to estimate standard deviation of the effects. Significant effects in half normal plots are detected through visual inspection (29). The slope of the line through the effects assumed to be non-significant gives an estimate of the standard deviation ( $\sigma$ ) of the error. From Figure 2 it can be concluded that plant extract, Concentration of Silver Nitrate solution and sunlight has greater impact on AgNp synthesis. The silver nitrate solution serves as the major donor of the silver ion contributing for the synthesis of silver nanoparticles. Sunlight act as a photo catalyst in the reduction of silver ion. The plant extract has protein, nitrate reductase which acts as an reducing agent in the reduction process[30]. Therefore, at high and low $\mathrm{pH}$, less accumulation of nanoparticles may occur due to the aggregation of the protein structure [31,32] The three parameters (plant extract, Concentration of Silver Nitrate solution and sunlight) which have a greater influence on the silver nanoparticle synthesis were selected for Box Behnken design.

\section{Box Behnken Design (BBD):}

A Box-Behnken experimental design with 3 independent variables at 3 different levels, low (-1), medium (0) and high (+1) was used to study the effects on dependent variables. A Box-Behnken experimental design has the advantage of requiring less experiments ( 15 batches) than would a full factorial design ( 27 batches). Table 6 shows the Box-Behnken experimental design and yield of silver nanoparticle obtained through experimentation.

The results of ANOVA analysis are depicted in Table 7. The F value, $\mathrm{p}$-value, MS value indicate that the relation between the response and the selected parameters is statistically significant [33]. The adequacy of the model developed was evaluated based on the correlation coefficient $\mathrm{R}^{2}$ and standard deviation value [34]. The closer the $\mathrm{R}^{2}$ value of unity and smaller the standard deviation implying more accurate response and repeatability that could be predicted by the model. The $\mathrm{R}^{2}$ and $\mathrm{R}^{2}$-(adj.) for Piper betle were obtained as 1 and 1 whereas for Jatropha curcas were obtained as 1 and 0.9999 respectively. The compatibility of $\mathrm{R}^{2}$ to $\mathrm{R}^{2}$ means a good adaptation of the theoretical values for the experimental data of the model [35]. The model can be considered as a practical model for the prediction of the factors within the tested ranges.

By applying multiple regression analysis on the experimental data, the following second order polynomial equation was found to explain the silver nanoparticle synthesize from piper betel (3) and Jatropha curcas (4) plant extract by only considering the significant terms and is shown below:

$Y=35.4116+20.5793 X_{1}-16.4444 X_{1}^{2}+38.9287 X_{2}-12.8528 X_{2}^{2}-0.2572 X_{3}+0.0023 X_{3}^{2}-57.9182 X_{1} X_{2}(3)$

$Y=48.9731-83.4124 X_{1}+112.5000 X_{1}{ }^{2}+2.9125 X_{2}+0.2653 X_{2}{ }^{2}+0.1811 X_{3}-0.0011 X_{3}{ }^{2}-0.0082 X_{1} X_{2}-0.0011 X_{1} X_{3}+0.0002 X_{2} X_{3}(4)$

The value of the correlation coefficient $\left(R^{2}\right)$ of Equation (3) and (4) was found to be 0.99 and 1 respectively, indicating a very good fit. The results clearly indicate that the $Y$ (Yield of Silver nanoparticles) value is strongly affected by the variables selected for the study. This is also reflected by the wide range of values for coefficients of the terms of Equation 3 and 4 . The main effects of $X_{1}, X_{2}$, and $X_{3}$ represent the average result of changing 1 variable at a time from its low level to its high level. The interaction terms $\left(X_{1} X_{2}, X_{1} X_{3}, X_{2} X_{3}, X_{1}{ }^{2}, X_{2}{ }^{2}\right.$, and $\left.X_{3}{ }^{2}\right)$ show how $Y$ changes when 2 variables are simultaneously changed. The negative coefficients for all 3 independent variables indicate an unfavorable effect on $Y$, while the positive coefficients for the interactions between 2 variables $\left(X_{1}, X_{2}\right.$ and $\left.X_{3}{ }^{2}\right)$ indicate a favorable effect on $Y$. Among the 3 independent variables, the lowest coefficient value is for $X_{2} X_{3}$ in equation 3 and 4 , indicating that this variable is insignificant in prediction of $\mathrm{Y}$.

The relationship between the dependent and independent variables was further elucidated by constructing contour plots.

Figure $4 \mathrm{~A}$ shows the Response surface plot and contour plot of silver nanoparticle synthesis from Piper betle extract and (i) shows the effect of Silver nitrate $(\mathrm{mM})$ and plant extract on Silver Nanoparticle synthesis. It was obvious that when silver nitrate was at a low level, the effect of plant extract was negligible. When the silver nitrate concentration was at a higher level, silver nanoparticle synthesis steadily increased with increasing $\mathrm{Y}$ as $55 \mu \mathrm{g} / \mathrm{mL}$. (ii) shows the effect of Sunlight exposure and Silver Nitrate on Silver Nanoparticle synthesis on increasing the silver nitrate concentration with increase in time of sunlight exposure with $\mathrm{Y}$ as $50 \mu \mathrm{g} / \mathrm{mL}$ (iii) shows the effect of Sunlight exposure and Plant extract on Silver Nanoparticle Synthesis. The yield of silver nanoparticles steadily increased with the increase in time of sunlight exposure and silver nitrate concentration showing Y as $48 \mu \mathrm{g} / \mathrm{mL}$.

Figure 4 B shows the Response surface plot and contour plot of silver nanoparticle synthesis from Jatropha extract Piper betle extract and (i) shows the effect of Silver nitrate $(\mathrm{mM})$ and plant extract on Silver Nanoparticle synthesis.. It was obvious that when silver nitrate was at a low level, the effect of plant extract was negligible. When the silver nitrate concentration was at a higher level, silver nanoparticle synthesis steadily increased with increasing $\mathrm{Y}$ as $56 \mu \mathrm{g} / \mathrm{mL}$. (ii) shows the effect of Sunlight exposure and Silver Nitrate on Silver Nanoparticle synthesis on increasing the silver nitrate concentration with increase in time of sunlight exposure with $\mathrm{Y}$ as $48 \mu \mathrm{g} / \mathrm{mL}$ (iii) shows the effect of Sunlight exposure and Plant extract on Silver Nanoparticle Synthesis. The yield of silver nanoparticles steadily increased with the increase in time of sunlight exposure and silver nitrate concentration showing $\mathrm{Y}$ as $54 \mu \mathrm{g} / \mathrm{mL}$.

The 3D response surface plots clearly show the complex interaction of the silver nitrate concentration, plant extract and the sunlight influence on the synthesize of silver nanoparticle. The plots indicate the linear relationship with incremental increase in yield of synthesis of silver nanoparticle. Like 3D response surface plots, 2D contour plots describe the analogues interpretation on relationship between the factors. Thus indicating the importance of the three parameters i) the silver nitrate, the donor of the silver ions for the synthesis [36], ii) the plant extract which is the biological reducing agent due to the presence of the nitrate reductase in synthesizing the silver nanoparticles [37] and iii) sunlight which act as a photo catalyst in the synthesis of silver nanoparticle $[38,39]$. This method of synthesis of silver nanoparticles through a green approach proves to be much effective and cheap method as it requires the natural plant extract and sunlight as a catalyst. 
The observed and the predicted yield of silver nanoparticle synthesis is shown in Figure 5 from a)Piper betle and b) Jatropha curcas plant extract versus the predicted yield of silver nanoparticles and found that the BBD predictions are more accurate and near to the regression line suggesting the superiority of BBD in predicting silver nanoparticle synthesis. The clustering and concordance of points around the diagonal line confirms the compatibility of the model to predict the experiments.

\section{Characterization of Silver nanoparticles by SEM:}

SEM analysis gives the size and shape of nanoparticles produced. Average particle size of silver nano-particles from Jatropha curcas was found to be $42 \mathrm{~nm}$ whereas from Piper betel, it was found to be $41 \mathrm{~nm}$. The nanoparticles produced were of uniform size and spherical in shape (Figure 6 ). Thus through optimization of the critical factors stable uniform sized and shaped particles were generated.

\section{Conclusion}

In the present study, stable silver nanoprticles were green synthesized via biological reduction method with the help of Piper betle and Jatropha curcas extract. The major factors affecting the sythesize of nanoparticles were optimized using statistical tools. Statistical optimization of factors affecting the synthesize of silver nanoparticlea using Plackett-Burman and Box-Behnken design appears to be a valuable tool for the syntheis of silver nanoparticle from Piper betle and Jatropha curcas. This study on varying nine different parameters on the synthesis of silver nanoparticle by Plackett Burman shows the optimum paramters to be chosen while synthesing the silver nanoparticle. It is very clear from the statistical model that the parameters like plant extract, silver nitrate concentration and sunlight has greater influence on the synthesis of the silver nanoparticle. This was further analyzed by Box Behnken design. The plant extract serve as a source of reducing agent, silver nitrate solution serve as a donor for silver ions and sunlight acts as a catalyst enhancing the activation energy of the molecules and thereby giving more yeild for the nanoparticle synthesis. The yeild of silver nanoprtucles can be increased by chosing the proper parameters and maintaining the optimal conditions. The BBD shows an obvious interaction between the parameters and hence proving the significance of the model. More stable and uniform sized nanoparticle were synthesized by optimizing the critical factors for the green synthesis of silver nanoparticle. Thus proving the green synthesis of silver nanoparticle is a cost effective, economic and stable method of synthesis.

\section{Materials And Methods}

\section{Green synthesis of Silver nanoparticle:}

The synthesis of silver nanoparticles was carried out from two leaf sources, Piper betle and Jatropha curcas under the optimized conditions. The leaves were washed thoroughly and air dried to remove the moisture. Phytochemical analysis were carried out to find the components in the leaf extract. 10 gm of the dried leaves were then crushed in mortar and pestle by adding adequate water making a solution of $100 \mathrm{ml}$. This solution was then filtered using Whatman No.1 filter paper. The synthesized nanoparticles were collected by centrifugation and washed twice with distilled water to remove any contaminants.

\section{Optimization of Silver nanoparticle:}

The optimization of variables for the synthesis of silver nanoparticles was carried out by Plackett Burman design. Nine factors ( $\mathrm{pH}$, temperature, pressure, time of reaction, microwave radiation, UV radiation, concentration of plant extract, silver nitrate and sunlight) were used for analysis. All factors were tested in triplicates (S-1 to S-24). The maximum and minimum limits of experimental factors were determined in preliminary experiments. Aqueous solution of silver nitrate $\left(\mathrm{AgNO}_{3}\right)$ was prepared in distilled water. The leaf extract of Piper betel and Jatropha curcas was added to $\mathrm{AgNO}_{3}$ solution and stirred continuously. Color change of the leaf extract was observed and optical density was noted at $430 \mathrm{~nm}$ using UV-Visible Spectrophotometer. After stabilization of reaction, a pellet was prepared by taking $20 \mathrm{ml}$ of silver nanoparticles solution in falcon tubes and centrifuged at $10000 \mathrm{rpm}$ for $15 \mathrm{~min}$. Pellet was thoroughly purified by washing repeatedly with distilled $\mathrm{H}_{2} \mathrm{O}$ and centrifuging for $10 \mathrm{~min}$ at $10000 \mathrm{rpm}$. Pellet was air dried for about 24 hrs. The yield for all the samples were calculated from the standard graph using the standard equation:

$y=0.33 x+0.068$, where $y$ is the optical density and

$\mathrm{x}$ is the concentration of silver nanoparticle.

\section{Plackett Burman design:}

PBD was applied to detect the best three significant variables and thereby improve the sequential optimization of process variables (8).PBD is much used for screening experiments, finding out the much impacted factors and heavily confounded with 2 factor interactions. It is a two factorial design and can identify the critical parameters required for elevated synthesis of silver nanoparticles by screening " $n$ " variables through $n+1$ experiments. The experimental design screening of the variables is presented in Table 1.

PBD assumes that each parameter is independent and can be described by the first-order model:

$Y=\beta_{0}+\sum \beta_{i}+X_{i},(1)$

where $Y$ is the predicted target response (extraction yields of silver nanoparticles), $\beta_{0}$ : the model intercept, $\beta_{\mathrm{i}}$ : the regression coefficient, $\mathrm{X}_{\mathrm{i}}$ : an independent parameter.

All the variables selected for the study were denoted as numerical factors and investigated at two level intervals designated as -1 for low level and +1 for high level. A nine factor Placket Burman design was used to study the effect of variables on synthesis of silver nanoparticles. Variables chosen were $\mathrm{pH} \mathrm{X}_{1}(2,10)$, 
temperature, $\mathrm{X}_{2}\left(20^{\circ} \mathrm{C}, 100^{\circ} \mathrm{C}\right)$, Pressure $\mathrm{X}_{3}(5 \mathrm{psi}, 15 \mathrm{psi})$, Time of reaction $\mathrm{X}_{4}(2 \mathrm{mins}, 90 \mathrm{mins})$, , Microwave radiation $\mathrm{X}_{5}(10$ secs, 40 sec $)$, UV radiation $\mathrm{X}_{6}(10 \mathrm{mins}$, $40 \mathrm{mins})$, concentration of plant extract, $X_{7}(0.1 \mathrm{~g} / \mathrm{ml}, 0.4 \mathrm{~g} / \mathrm{ml})$, silver nitrate $X_{8}(0.001 \mathrm{M}, 0.01 \mathrm{M})$ and sunlight $X_{9}(10 \mathrm{mins}, 90 \mathrm{mins})$. $X_{10}$ and $X_{11}$ are considered as dummy variables. The values represented are lower (-) and upper limit (+) of each variable. The maximum and minimum limits for analysis were decided after performing a set of 14 preliminary experiments. Analysis was done using Statistica software which generated a 12 run table for 9 factors. All experiments were performed in triplicates to minimize experimental errors. Dummy variables $\left(\mathrm{X}_{10}\right.$ and $\left.\mathrm{X}_{11}\right)$ are used to estimate experimental errors in data analysis. Triplicates of all experiments were done and mean of AgNps biosynthesized was taken as the response. Based on the biosynthesized AgNps, the factorial experiment was analyzed using regression analysis and ANOVA.

\section{Box Behnken Design:}

The Box-Behnken design is a response surface methodology (RSM) design that requires only three levels (low, middle and high) to run an experiment. BBD was used to further optimize the synthesize conditions and was based on the parameters that were already screened as being significant factors by PBD. Plant extract $\left(X_{1}\right)$, concentration of silver nitrate $\left(X_{2}\right)$, and sunlight exposure $\left(X_{3}\right)$ were selected for further optimization, with fluctuation ranges of $0.1-0.4$ $\mathrm{g} / \mathrm{mL}, 0.1-1 \mathrm{mM}$ and 30-90 min respectively. Each experiment was performed in triplicate. Analysis of variance (ANOVA) was used to analyze the experimental data from 17 experiments and the results were fitted by the response surface regression:

$Y=\beta_{0}+\sum \beta_{i}+X_{i}+\sum \beta_{i i}+X_{i}^{2}+\sum \beta_{i j}+X_{i j}(2)$

where $Y$ is the predicted response, $X i X j$ represents coded independent variables, $\beta_{0}$ is the offset term, $\beta_{i}$ is the $i^{\text {th }}$ linear coefficient, $\beta_{i i}$ is the $i^{\text {th }}$ quadratic coefficient, and $\beta_{\mathrm{ij}}$ is the $\mathrm{ij}^{\text {th }}$ interaction coefficient. Statictica software was employed for experimental design as well as for regression and graphical analysis of the experimental data.

\section{Characterization of Silver nanoparticle by SEM analysis:}

After finding out the optimized parameters having major effect on the synthesis of nanoparticle, silver nanoparticles were synthesized at those optimized conditions. The size and shape of the nanoparticles synthesized were studied using SEM analysis. The characterization of the silver nanoparticles was carried out by Carl Zeiss ultra 55 SEM.

\section{Declarations}

\section{Acknowledgement:}

The authors would like to thank the Department of Biotechnology, Sir M Visvesvaraya Institute of Technology for carrying out the research work and also Deaprtment of Chemical Engineering, M.S Ramaiah Institute of Technology for constant support and encouragement.

\section{Conflict of Intereset:}

The authors have no conflict of interest to declare

\section{Ethics approval and consent to participate:}

Not Applicable

\section{Consent for publication:}

The authors have given consent to publish this article.

\section{Availability of data and material:}

Not Applicable

\section{Funding:}

Not Applicable

\section{Authors' contributions}

Author Halima carried out the experimental work planning and execution. The optimization parameters selections, review of literature, calculation of the impact of the parameter s were decided. Author Dr. Archana contributed in editing, planning and overall guidance. Author Dr. Sivakiran contributed in modeling using software Statistica 7. All the authors read and approved the final manuscript.

\section{References}

[1] Dahl JA, Maddux BLS, Hutchison JE. Chem Rev 2007;107:2228.

[2] Hutchison JE. ACSNano 2008;2:395 
[3] Khanna PK, Singh N, Charan S, Subbarao VVVS, Gokhale R, and Mulik UP (2005) Synthesis and characterization of Ag/PVA nanocomposite by chemical reduction method. Mater Chem Phys 93, 117-21.

[4]. Jia H, Zeng J, Song W, An J, and Zhao B (2006) Preparation of silver nanoparticles by photo-reduction for surface-enhanced Raman scattering. Thin Solid Films 496, 281-7.

[5]. Long D, Wu G, and Chen S (2007) Preparation of oligochitosan stabilized silver nanoparticles by gamma irradiation. Radiat Phys Chem 76, $1126-31$.

[6]. Rao JP and Geckeler KE (2011) Polymer nanoparticles: Preparation techniques and size-control parameters. Prog Polyme Sci 36, 887-913.

[7] Bar, H., Bhui, D.K., Sahoo, G.P., Sarkar, P., De, S.P. and Misra, A., 2009. Green synthesis of silver nanoparticles using latex of Jatropha curcas. Colloids and surfaces A: Physicochemical and engineering aspects, 339(1-3), pp.134-139.

[8] Korbekandi, H., Iravani, S. and Abbasi, S., 2012. Optimization of biological synthesis of silver nanoparticles using Lactobacillus casei subsp. casei. Journal of Chemical Technology \& Biotechnology, 87(7), pp.932-937.

[9] El-Naggar, N.E.A. and Abdelwahed, N.A., 2014. Application of statistical experimental design for optimization of silver nanoparticles biosynthesis by a nanofactory Streptomyces viridochromogenes. Journal of Microbiology, 52(1), pp.53-63.

[10] S.S. Shankar, A. Rai, A. Ahmad, M. Sastry, Rapid synthesis of Au, Ag, and bimetallic Au core-Ag shell nanoparticles using Neem (Azadirachta indica) leaf broth, J. Colloids Interf. Sci. 275 (2004) 496-502.

[11] S.P. Chandran, M. Chaudhary, R. Pasricha, A. Ahmad, M. Sastry, Synthesis of gold nanotriangles and silver nanoparticles using Aloe vera plant extract, Biotechnol. Prog. 22 (2006) 577-588.

[12] Jha AK, Prasad K, Prasad K, Kulkarni AR. Plant system: nature's nanofactory. Colloids Surf B Biointerfaces. 2009;73(2):219-223.

doi:10.1016/j.colsurfb.2009.05.018 [13] R.W. Raut, J.R. Lakkakula, N.S. Kolekar, V.D. Mendhulkar, S.B. Kashid, Phytosynthesis of silver nanoparticle using Gliricidia sepium, Curr. Nanosci. 5 (2009) 117-122.

[13] Raut Rajesh, W., Lakkakula Jaya, R., Kolekar Niranjan, S., Mendhulkar Vijay, D. and Kashid Sahebrao, B., 2009. Phytosynthesis of silver nanoparticle using Gliricidia sepium (Jacq.). Curr. Nanosci, 5(1), pp.117-122.

[14] S.P. Dubey, M. Lahtinen, M. Sillanpa, Green synthesis and characterizations of silver and gold nanoparticles using leaf extract of Rosa rugosa, Colloids Surf. A. 364 (2010) 34-41.

[15] A.D. Dwivedi, K. Gopal, Biosynthesis of silver and gold nanoparticles using Chenopodium album leaf extract, Colloids Surf. A. 369 (2010) $27-33$.

[16] A.K. Jha, K. Prasad, Green synthesis of silver nanoparticles using Cycas Leaf, Int. J. Green Nanotechnol. 1 (2010) $110-117$.

[17] C. Krishnaraj, E.G. Jagan, S. Rajasekar, P. Selvakumar, P.T. Kalaichelvan, N. Mohan, Synthesis of silver nanoparticles using Acalypha indica leaf extracts and its antibacterial activity against water borne pathogens, Colloids Surf. B.: Biointerf. 76 (2010) 50-56.

[18] L. Lin, W. Wang, J. Huang, Q. Li, D. Sun, X. Yang, H. Wang, N. He, Y. Wang, Nature factory of silver nanowires: plant mediated synthesis using broth of Cassia fistula leaf, Chem. Eng. J. 162 (2010) 852-858.

[19] D. Philip, Green synthesis of gold and silver nanoparticles using Hibiscus rosasinensis, Phys. E. 42 (2010) 1417-1424.

[20] N. Roy, A. Barik, Green synthesis of silver nanoparticle from the unexploited weed resources, Int. J. Nanotechnol. Appl. 4 (2010) 95-101.

[21] D. Raghunandan, B. Mahesh, S. Basavaraja, S. Balaji, S. Manjunath, A. Venkataraman, Microwave-assisted rapid extracellular synthesis of stable biofunctionalized silver nanoparticles from guava (Psidium guajava) leaf extract, Nanoparticle J. Res. 13 (2011) 2021-2028. ACCEPTED MANUSCRIPT ACCEPTED MANUSCRIPT 18

[22] R. Veerasamy, T.Z. Xin, S. Gunasagaran, T.F.W. Xiang, E.F.C. Yang, N. Jeyakumar, S.A. Dhanaraj, Biosynthesis of silver nanoparticles using mangosteen leaf extract and evaluation of their antimicrobial activities, J. Saudi Chem. Soc. 15 (2011) 113-120.

[23] D. Philip, C. Unni, Extracellular biosynthesis of gold and silver nanoparticles using Krishna tulsi (Ocimum Sanctum) leaf and nanostructures, Phys. E. 43 (2011) $1318-1322$.

[24] S.M. Roopan, G. Rohit Madhumitha, A. Abdul Rahuman, C. Kamaraj, A. Bharathi, T.V. Surendra, Low-cost and eco-friendly phyto-synthesis of silver nanoparticles using Cocosnucifera coir extract and its larvicidal activity, Ind. Crops Prod. 43 (2012) 631- 635.

[25] J.L. Gardea-Torresedey, G. Gombez, M. Jose-Yaceman, J.G. Parsons, J.R. PeraltaVidea, M.T. Jose-Yacaman, Alfalfa sprouts: A Natural Source for the synthesis of silver nanoparticles, Langmuir. 19 (2003) 1357-1361

[26]. Salihu, A., Alam, M.Z., AbdulKarim, I.M.and Salleh, H.M. 2011. Optimization of lipase production by Candida cylindracea in palm oil mill effluent based medium using statistical experimental design. J. Mol. Catal. B: Enzymatic. 69: 66-73.

Page $7 / 14$ 
[27]. Hassan, M., Essam, T., Yassin, A.S., Salama, A., 2016. Optimization of rhamnolipid production by biodegrading bacterial isolates using Plackett-Burman design. Int. J. Biol. Macromol. 82, 573-579.

[28] Aghaiea E., Pazouki M., Hosseini M.R., Ranjbara M., Ghavipanjeh F., Response Surface Methodology (RSM) Analysis of Organic Acid Production for Kaolin Beneficiation by Aspergillus Niger, Chemical Engineering Journal, 147:245-251 (2009).

[29]. K. Vanaja \& R.H. Shobha Rani (2007) Design of Experiments: Concept and Applications of Plackett Burman Design, Clinical Research and Regulatory Affairs, 24:1, 1-23,

[30] Kamali M., Ghorashi S.A.A., Asadollahi M.A., Controllable Synthesis of Silver Nanoparticles Using Citrate as Complexing Agent: Characterization of Nanopartciles and Effect of pH on Size and Crystallinity, Iranian Journal of Chemistry and Chemical Engineering, (IJCCE), 31(4):21-28 (2012).

[31] Salunkhe R.B., Patil S.V., Salunke B.K., Patil C.D., Sonawane A.M., Studies on Silver Accumulation and Nanoparticles Synthesis by Cochlioboluslunatus, Applied Biochemical Biotechnology, 165(1):221:234 (2011).

[32] Sadowski Z., Maliszewska I.H., Grochowalska B., Polwczyk I., Kozlecki T., Synthesis of Silver Nanoparticles Using Microorganisms, Materials SciencePoland, 26(2):419-424, (2008).

[33] Hasnain, M.S., Javed, M.N., Alam, M.S., Rishishwar, P., Rishishwar, S., Ali, S., Nayak, A.K. and Beg, S., 2019. Purple heart plant leaves extract-mediated silver nanoparticle synthesis: Optimization by Box-Behnken design. Materials Science and Engineering: C, 99, pp.1105-1114.

[34] A.K. Nayak, D. Pal, J. Pradhan, M.S. Hasnain, Fenugreek seed mucilage-alginate mucoadhesive of metformin HCl: Design, optimization and evaluation, Int. J. Biol. Macromol. 54 (2013) 144-154.

[35] M.S. Hasnain, S. Rao, M.K. Singh, N. Vig, A. Gupta, A. Ansari, P. Sen, P. Joshi, S.A. Ansari, Development and validation of LC-MS/MS method for the quantitation of lenalidomide in human plasma using Box-Behnken experimental design, Analyst. 138 (2013) 1581-1588.

[36] Brito, T. K., Viana, R. L. S., Moreno, C. J. G., da Silva Barbosa, J., de Sousa Júnior, F. L., de Medeiros, M. J. C., ... \& Rocha, H. A. O. (2020). Synthesis of Silver Nanoparticle Employing Corn Cob Xylan as a Reducing Agent with Anti-Trypanosoma cruzi Activity. International Journal of Nanomedicine, $15,965$.

[37] Albeladi, S. S. R., Malik, M. A., \& Al-thabaiti, S. A. (2020). Facile biofabrication of silver nanoparticles using Salvia officinalis leaf extract and its catalytic activity towards Congo red dye degradation. Journal of Materials Research and Technology, 9(5), 10031-10044.

[38] Rawat, V., Sharma, A., Bhatt, V. P., Singh, R. P., \& Maurya, I. K. (2020). Sunlight mediated green synthesis of silver nanoparticles using Polygonatum graminifolium leaf extract and their antibacterial activity. Materials Today: Proceedings.

[39] Mankad, M., Patil, G., Patel, D., Patel, P., \& Patel, A. (2020). Comparative studies of sunlight mediated green synthesis of silver nanoparaticles from Azadirachta indica leaf extract and its antibacterial effect on Xanthomonas oryzae pv. oryzae. Arabian Journal of Chemistry, 13(1), $2865-2872$.

\section{Tables}

Table 1: Experimental variables (independent) at two levels (low and high) affecting the synthesis of AgNPs

\begin{tabular}{|clll|}
\hline S. N & Parameters & High Yield $(+1)$ & Low Yield $(-1)$ \\
\hline 1. & $\mathrm{pH}\left(\mathrm{X}_{1}\right)$ & 10 & 2 \\
\hline 1. & Temperature $\left(\mathrm{X}_{2}\right)$ (degree Celsius) & 100 & 20 \\
\hline 1. & Pressure $\left(\mathrm{X}_{3}\right)(\mathrm{psi})$ & 15 & 5 \\
\hline 1. & Time $\left(\mathrm{X}_{4}\right)($ mins $)$ & 2 & 90 \\
\hline 1. & Microwave Radiation $\left(\mathrm{X}_{5}\right)($ secs $)$ & 40 & 10 \\
\hline 1. & UV Radiation $\left(\mathrm{X}_{6}\right)$ exposure $(\mathrm{mins})$ & 20 & 10 \\
\hline 1. & Concentration of plant extract $\left(\mathrm{X}_{7}\right)(\mathrm{g} / \mathrm{ml})$ & 0.1 & 0.4 \\
\hline 1. & Silver Nitrate $\left(\mathrm{X}_{8}\right)(\mathrm{mM})$ & 1 & 0.25 \\
\hline 1. & Sun Light $\left(\mathrm{X}_{9}\right)(\mathrm{mins})$ & 90 & 10 \\
\hline
\end{tabular}


Table 2: Plackett Burman design for evaluation of 9 independent variables $\left(\mathrm{X}_{1}-\mathrm{X}_{9}\right)$ for synthesis of silver nanoparticles from a) Jatropha curcas extract b) Piper betle extract

\begin{tabular}{|c|c|c|c|c|c|c|c|c|c|c|c|c|c|}
\hline \multicolumn{12}{|c|}{ Design: 11 Factor Screening Design (Spreadsheet1) } & \multirow{2}{*}{$\begin{array}{l}\quad \text { Piper betle } \\
\text { Yield } \\
(\mu \mathrm{g} / \mathrm{mL})\end{array}$} & \multirow{2}{*}{$\begin{array}{l}\text { Jatropha curcas } \\
\text { Yield }(\mu \mathrm{g} / \mathrm{mL})\end{array}$} \\
\hline Run & $\mathrm{X}_{1}$ & $x_{2}$ & $x_{3}$ & $\mathrm{X}_{4}$ & $X_{5}$ & $X_{6}$ & $\mathrm{x}_{7}$ & $\mathrm{X}_{8}$ & $X_{9}$ & $\mathrm{X}_{10}$ & $\mathrm{X}_{11}$ & & \\
\hline 1 & 1 & -1 & 1 & -1 & -1 & -1 & 1 & 1 & 1 & -1 & 1 & 41.51 & 41.53 \\
\hline 2 & 1 & 1 & -1 & 1 & -1 & -1 & -1 & 1 & 1 & 1 & -1 & 34.64 & 35.04 \\
\hline 3 & -1 & 1 & 1 & -1 & 1 & -1 & -1 & -1 & 1 & 1 & 1 & 29.2 & 29.11 \\
\hline 4 & 1 & -1 & 1 & 1 & -1 & 1 & -1 & -1 & -1 & 1 & 1 & 24.58 & 24.26 \\
\hline 5 & 1 & 1 & -1 & 1 & 1 & -1 & 1 & -1 & -1 & -1 & 1 & 33.56 & 33.58 \\
\hline 6 & 1 & 1 & 1 & -1 & 1 & 1 & -1 & 1 & -1 & -1 & -1 & 30.012 & 30.91 \\
\hline 7 & -1 & 1 & 1 & 1 & -1 & 1 & 1 & -1 & 1 & -1 & -1 & 33.75 & 33.31 \\
\hline 8 & -1 & -1 & 1 & 1 & 1 & -1 & 1 & 1 & -1 & 1 & -1 & 40.45 & 36.72 \\
\hline 9 & -1 & -1 & -1 & 1 & 1 & 1 & -1 & 1 & 1 & -1 & 1 & 31.38 & 30.97 \\
\hline 10 & 1 & -1 & -1 & -1 & 1 & 1 & 1 & -1 & 1 & 1 & -1 & 32.49 & 32.09 \\
\hline 11 & -1 & 1 & -1 & -1 & -1 & 1 & 1 & 1 & -1 & 1 & 1 & 31.04 & 30.57 \\
\hline 12 & -1 & -1 & -1 & -1 & -1 & -1 & -1 & -1 & -1 & -1 & -1 & 20.46 & 19.57 \\
\hline
\end{tabular}

Table 3: Regression coefficients, standard error, main effect, P-value for AgNPs synthesis

\begin{tabular}{|llllllllllll}
\hline & \multicolumn{1}{l}{ Piper Betle } & & & & \multicolumn{5}{c}{ Jatropha curcas } \\
\hline & Regressn & Std.Er. & $\mathrm{t}(2)$ & $\mathrm{P}$ & $-95 . \%$ & $+95 . \%$ & Regressn & Std.Err. & $\mathrm{t}(2)$ & $\mathrm{P}$ \\
\hline Mean/Interc & 26.3570 & 3.266337 & 8.06929 & 0.015013 & 12.3031 & 40.41093 & 27.3550 & 0.840485 & 32.5467 & 0.000064 & 24.6802 \\
\hline 1 & 0.3959 & 0.171321 & 2.31093 & 0.147043 & -0.3412 & 1.13305 & 0.2447 & 0.042753 & 5.7229 & 0.01110588 & 0.1086 \\
\hline 2 & 0.0115 & 0.017132 & 0.67323 & 0.570171 & -0.0622 & 0.08525 & 0.0031 & 0.004127 & 0.7608 & 0.502113 & -0.0100 \\
\hline 3 & 0.2644 & 0.137057 & 1.92909 & 0.193504 & -0.3253 & 0.85410 & 0.2861 & 0.034202 & 8.3641 & 0.003584 & 0.1772 \\
\hline 4 & 0.0000 & 0.000099 & 0.19435 & 0.863853 & -0.0004 & 0.00044 & 0.0256 & 0.004312 & 5.9396 & 0.009541 & 0.0119 \\
\hline 5 & 0.0403 & 0.045686 & 0.88239 & 0.470644 & -0.1563 & 0.23688 & 0.0627 & 0.011004 & 5.6984 & 0.010716 & 0.0277 \\
\hline 6 & -0.2551 & 0.136975 & -1.86207 & 0.203640 & -0.8444 & 0.33430 & -0.2782 & 0.037944 & -7.3327 & 0.005240 & -0.3990 \\
\hline 7 & -22.1021 & 4.568563 & -4.83786 & 0.040169 & -41.7590 & -2.44513 & -24.3112 & 1.140072 & -21.3243 & 0.000226 & -27.9394 \\
\hline 8 & 7.9253 & 1.827425 & 4.33685 & 0.049272 & 0.0625 & 15.78805 & 8.0498 & 0.456029 & 17.6520 & 0.000396 & 6.5985 \\
\hline 9 & 0.0589 & 0.017132 & 3.43941 & 0.075131 & -0.0148 & 0.13264 & 0.0502 & 0.004275 & 11.7440 & 0.001327 & 0.0366 \\
\hline
\end{tabular}

Table 4: Sum of Squares(SS), Degree of Freedom (Df), Mean square(MS), F-value (F), P-Value(p) 


\begin{tabular}{|c|c|c|c|c|c|c|c|c|c|c|}
\hline \multirow{2}{*}{$\begin{array}{l}\text { Plant extract } \\
\text { Parameters }\end{array}$} & \multicolumn{5}{|c|}{ Jatropha curcas } & \multicolumn{5}{|c|}{ Piper betle } \\
\hline & ss & Df & MS & $\mathbf{F}$ & $\mathbf{P}$ & ss & Df & MS & $\mathbf{F}$ & $\mathbf{P}$ \\
\hline$x_{1}$ & 10.6095 & 1 & 10.6095 & 32.7515 & 0.010588 & 22.5263 & 1 & 22.52632 & 5.34039 & 0.147043 \\
\hline$x_{2}$ & 0.1875 & 1 & 0.1875 & 0.5788 & 0.502113 & 1.9118 & 1 & 1.91183 & 0.45324 & 0.570171 \\
\hline$x_{3}$ & 22.6621 & 1 & 22.6621 & 69.9574 & 0.003584 & 15.6972 & 1 & 15.69723 & 3.72140 & 0.193504 \\
\hline$X_{4}$ & 11.4282 & 1 & 11.4282 & 35.2785 & 0.009541 & 0.1593 & 1 & 0.15933 & 0.03777 & 0.863853 \\
\hline$X_{5}$ & 10.5188 & 1 & 10.5188 & 32.4714 & 0.010716 & 3.2843 & 1 & 3.28428 & 0.77862 & 0.470644 \\
\hline$x_{6}$ & 17.4176 & 1 & 17.4176 & 53.7679 & 0.005240 & 14.6255 & 1 & 14.62548 & 3.46731 & 0.203640 \\
\hline$x_{7}$ & 147.3036 & 1 & 147.3036 & 454.7237 & 0.000226 & 98.7242 & 1 & 98.72420 & 23.40489 & 0.040169 \\
\hline$x_{8}$ & 100.9374 & 1 & 100.9374 & 311.5919 & 0.000396 & 79.3352 & 1 & 79.33524 & 18.80828 & 0.049272 \\
\hline $\mathrm{X}_{9}$ & 44.6781 & 1 & 44.6781 & 137.9205 & 0.001327 & 49.8983 & 1 & 49.89832 & 11.82957 & 0.075131 \\
\hline Error & 0.9718 & 3 & 0.3239 & & & 8.4362 & 2 & 4.21810 & & \\
\hline Total SS & 522.4125 & 12 & & & & 350.2704 & 11 & & & \\
\hline
\end{tabular}

Table 5: Observed and predicted values on yield of nanoparticles

\begin{tabular}{|lllllll|}
\hline \multicolumn{4}{|c}{ Piper betle } & & \multicolumn{5}{c|}{ Jatropha curcas } \\
\hline & Observed & Predicted & Resids & Observed & Predicted & Resids \\
\hline $\mathbf{1}$ & 41.53000 & 41.53987 & -0.00987 & 41.51000 & 41.66035 & -0.150352 \\
\hline $\mathbf{2}$ & 35.04000 & 35.03342 & 0.00658 & 34.64000 & 34.53977 & 0.100235 \\
\hline $\mathbf{3}$ & 29.11000 & 29.77382 & -0.66382 & 29.20000 & 29.03320 & 0.166802 \\
\hline $\mathbf{4}$ & 24.26000 & 23.54618 & 0.71382 & 24.58000 & 24.31296 & 0.267037 \\
\hline $\mathbf{5}$ & 33.58000 & 32.21551 & 1.36449 & 33.56000 & 33.66023 & -0.100235 \\
\hline $\mathbf{6}$ & 30.91000 & 31.62053 & -0.71053 & 30.01200 & 30.22892 & -0.216920 \\
\hline $\mathbf{7}$ & 33.31000 & 32.64618 & 0.66382 & 33.75000 & 33.91680 & -0.166802 \\
\hline $\mathbf{8}$ & 36.72000 & 36.71342 & 0.00658 & 40.45000 & 40.34977 & 0.100235 \\
\hline $\mathbf{9}$ & 30.97000 & 29.60222 & 1.36778 & 31.38000 & 31.43012 & -0.050117 \\
\hline $\mathbf{1 0}$ & 32.09000 & 33.45449 & -1.36449 & 32.49000 & 32.38977 & 0.100235 \\
\hline $\mathbf{1 1}$ & 30.57000 & 31.23053 & -0.66053 & 31.04000 & 30.82308 & 0.216920 \\
\hline $\mathbf{1 2}$ & 19.57000 & 20.28382 & -0.71382 & 20.46000 & 20.02352 & 0.436481 \\
\hline
\end{tabular}

Table 6: Box-Behnken experimental design and yield of silver nanoparticle 


\begin{tabular}{|c|c|c|c|c|c|}
\hline \multirow[t]{2}{*}{$\begin{array}{l}\text { Standard } \\
\text { Run }\end{array}$} & Plant Extract (g/mL) & $\mathrm{AgNO}_{3} \mathrm{mM}$ & Sunlight mins & $\begin{array}{l}\text { Experimental } \\
\text { (Piper betle) }\end{array}$ & $\begin{array}{l}\text { Experimental } \\
\text { (Jatropha curcas) }\end{array}$ \\
\hline & & & & Conc. $(\mu \mathrm{g} / \mathrm{mL})$ & Conc. $(\mu \mathrm{g} / \mathrm{mL})$ \\
\hline 1. & 0.100000 & 0.10000 & 60.00000 & 28.6 & 48.89 \\
\hline 2. & 0.400000 & 0.10000 & 60.00000 & 35.68 & 40.71 \\
\hline 3. & 0.100000 & 1.000000 & 60.00000 & 50.38 & 51.78 \\
\hline 4. & 0.400000 & 1.000000 & 60.00000 & 40.8 & 43.6 \\
\hline 5. & 0.100000 & 0.5000 & 30.00000 & 47.29 & 47.7 \\
\hline 6. & 0.400000 & 0.5000 & 30.00000 & 37.71 & 39.55 \\
\hline 7. & 0.100000 & 0.5000 & 90.00000 & 48.22 & 50.51 \\
\hline 8. & 0.400000 & 0.5000 & 90.00000 & 38.64 & 42.34 \\
\hline 9. & 0.250000 & 0.10000 & 30.00000 & 38.26 & 39.86 \\
\hline 10. & 0.250000 & 1.000000 & 30.00000 & 43.37 & 42.75 \\
\hline 11. & 0.250000 & 0.10000 & 90.00000 & 39.19 & 42.66 \\
\hline 12. & 0.250000 & 1.000000 & 90.00000 & 44.30 & 45.56 \\
\hline 13. & 0.250000 & 0.5000 & 60.00000 & 41.29 & 43.50 \\
\hline 14. & 0.250000 & 0.5000 & 60.00000 & 41.29 & 43.50 \\
\hline 15. & 0.250000 & 0.5000 & 60.00000 & 41.29 & 43.50 \\
\hline
\end{tabular}

Table 7: Analysis of variance for the influence of the selected variables on silver nanoparticle synthesis

\begin{tabular}{|c|c|c|c|c|c|c|}
\hline Source of plant & Source of variation & ss & Df & MS & $\mathbf{F}$ & $\mathbf{p}$ \\
\hline \multirow[t]{8}{*}{ Piper betel } & (1)Plant Extract $(\mathrm{g} / \mathrm{mL}) \mathrm{L}+\mathrm{Q}$ & 68.5189 & 2 & 34.25943 & 2.214639 & 0.204752 \\
\hline & (2)Silver Nitrate (mM) L+Q & 187.8295 & 2 & 93.91475 & 6.070949 & 0.045949 \\
\hline & (3)Sunlight Exposure (Min) L+Q & 17.1606 & 2 & 8.58029 & 0.554657 & 0.605960 \\
\hline & $1 * 2$ & 61.5135 & 1 & 61.51347 & 3.976427 & 0.102711 \\
\hline & $1 * 3$ & 0.0000 & 1 & 0.00000 & 0.000000 & 1.000000 \\
\hline & $2 * 3$ & 0.0000 & 1 & 0.00000 & 0.000000 & 1.000000 \\
\hline & Error & 77.3477 & 5 & 15.46954 & & \\
\hline & Total SS & 405.6015 & 14 & & & \\
\hline \multirow[t]{8}{*}{ Jatropha curcas } & (1)Plant Extract $(\mathrm{g} / \mathrm{mL}) \mathrm{L}+\mathrm{Q}$ & 156.1257 & 2 & 78.06283 & 567518.7 & 0.000000 \\
\hline & (2)Silver Nitrate (mM) L+Q & 16.8839 & 2 & 8.44195 & 61373.2 & 0.000000 \\
\hline & (3)Sunlight Exposure (Min) L+Q & 19.4413 & 2 & 9.72064 & 70669.3 & 0.000000 \\
\hline & $1 * 2$ & 0.0000 & 1 & 0.00000 & 0.0 & 0.928422 \\
\hline & $1 * 3$ & 0.0001 & 1 & 0.00010 & 0.7 & 0.432791 \\
\hline & $2 * 3$ & 0.0000 & 1 & 0.00003 & 0.2 & 0.672477 \\
\hline & Error & 0.0007 & 5 & 0.00014 & & \\
\hline & Total SS & 194.8668 & 14 & & & \\
\hline
\end{tabular}

\section{Figures}


a)

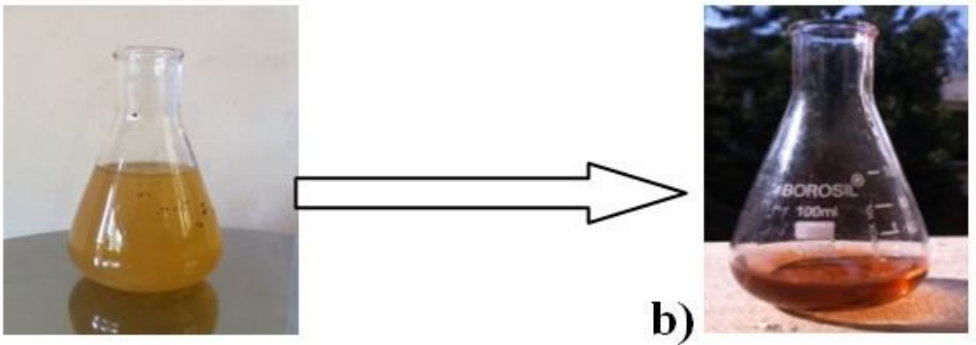

Figure 1

a) plant extract b) reduction to AgNp

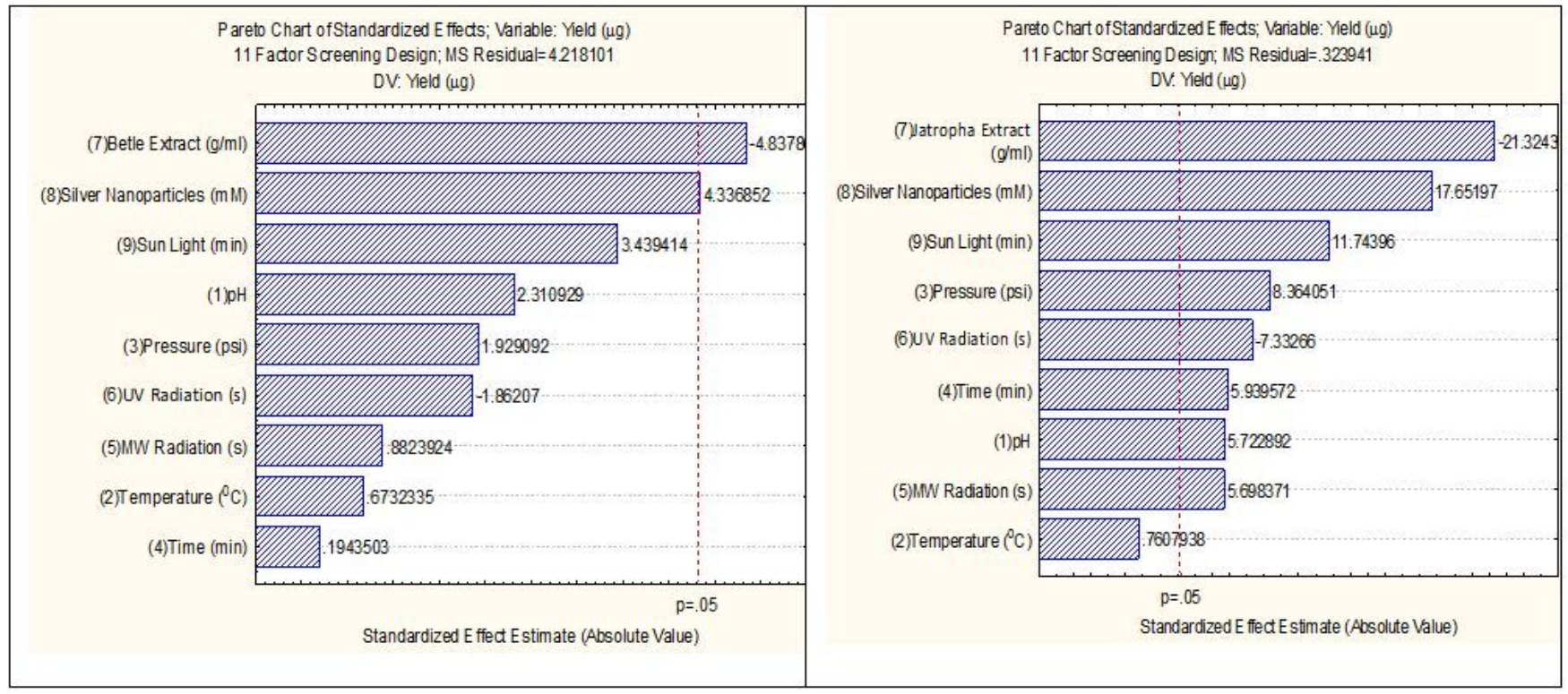

Figure 2

Pareto chart for standardized Effects a) Piper betle b) Jatropha curcas


\section{Figure 3}

Half-normal probability plot of effects for choosing the statistically significant effects in Plackett-Burman screening design. 

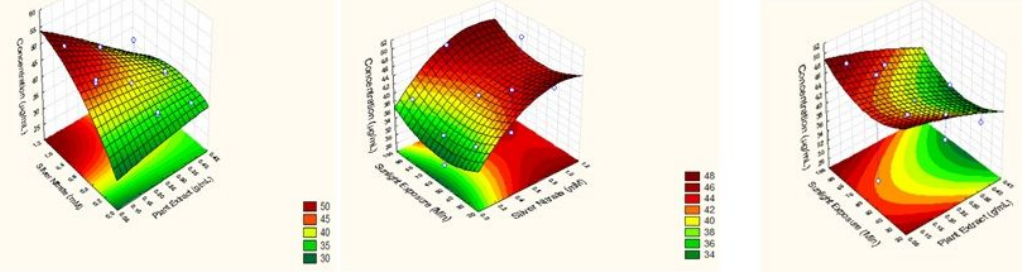

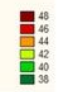
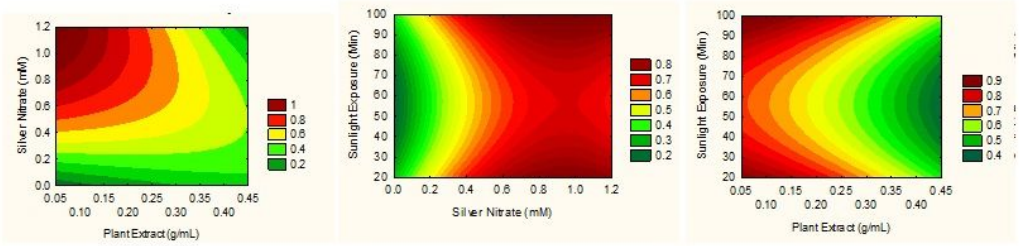

A. (i)

(ii)

(iii)
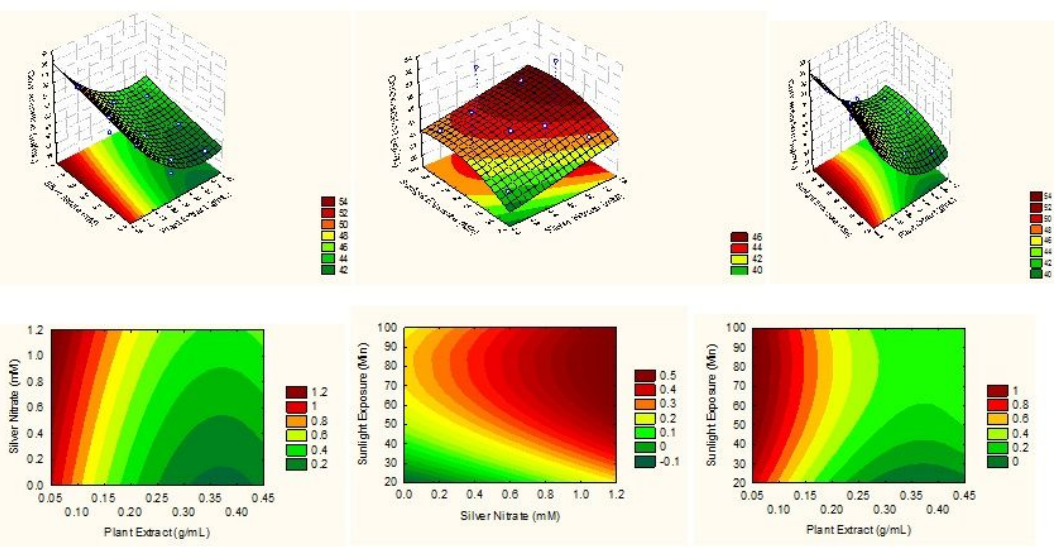

B. (i)

(ii)

(iii)

\section{Figure 4}

Response surface plot and contour plot of A) Piper betle and B)Jatropha curcas the combined effects of (i) Silver Nitrate and Plant extract (ii) Sunlight exposure and Silver Nitrate (iii) Sunlight exposure and Plant extract on Silver Nanoparticle Synthesis.
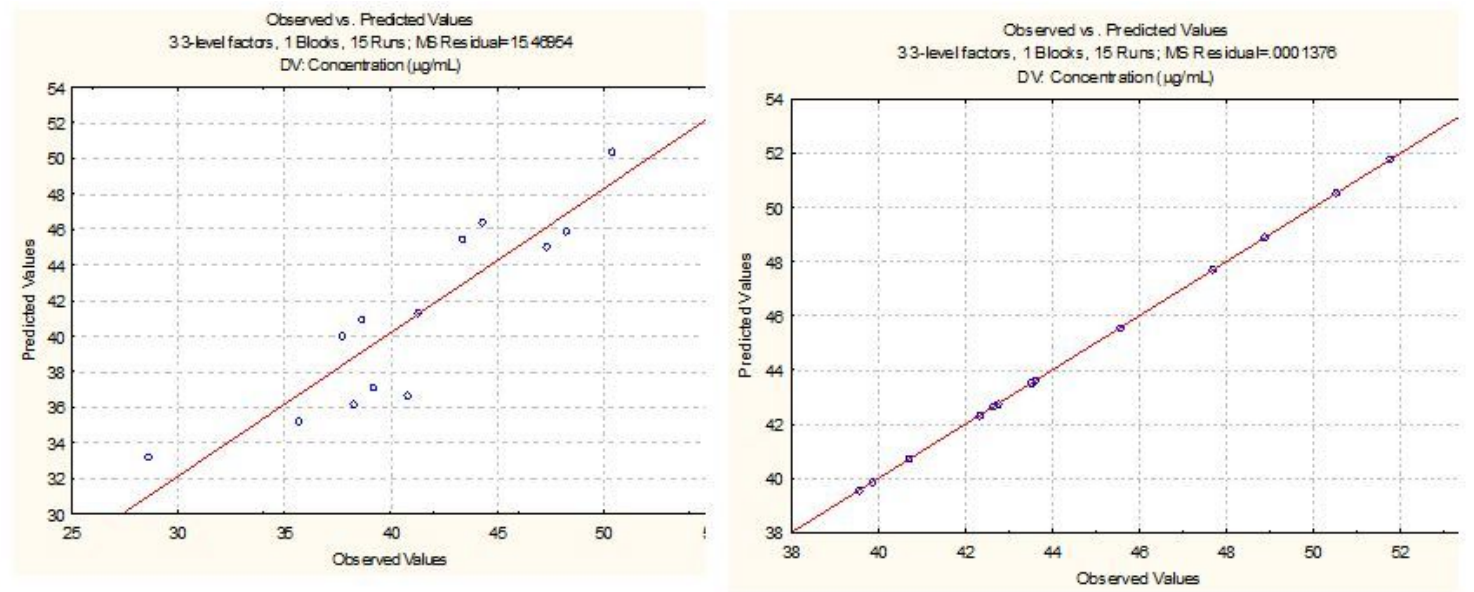

a)

b)

\section{Figure 5}

Observed and predicted value of yield of silver nanoparticle from a) Piper betle and b) Jatropha curcas plant extract (green synthesis) 


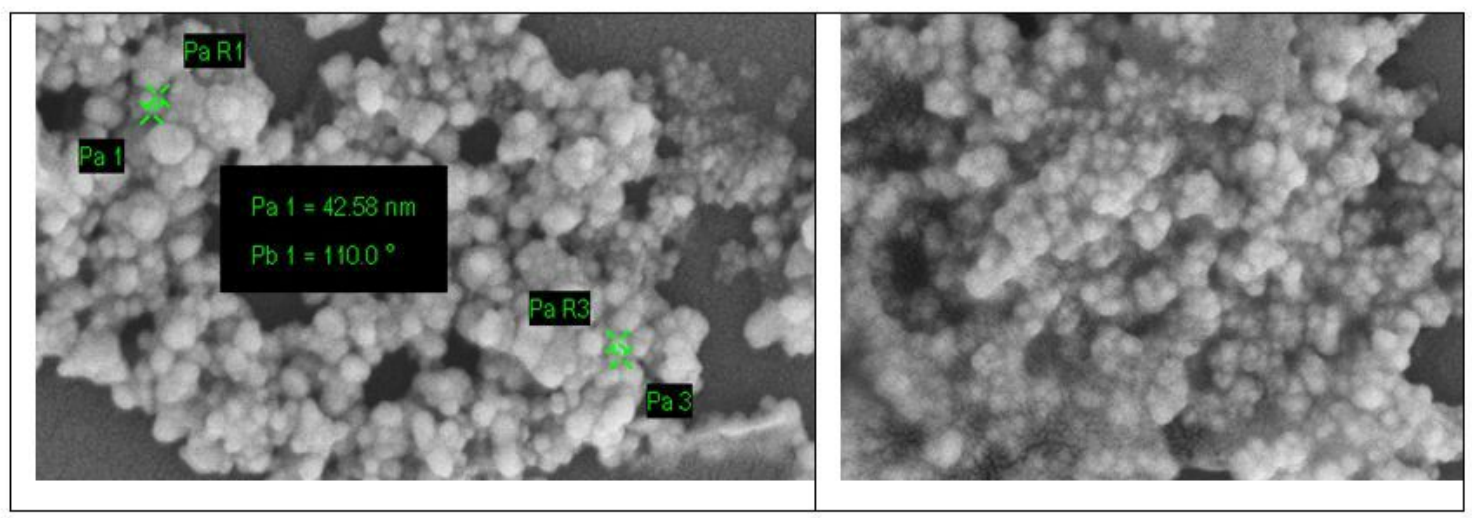

Figure 6

SEM image of silvernanoparticles from a)Jatropha curcas and b)Piper betle leaf extract 